\title{
Alan Pauls: vida de lector
}

Alan Pauls: Reader's life

Victor Emiliano Rodríguez Montiel

Recebido em: 10 de setembro de 2020

Aceito em: 11 de outubro de 2020
Emiliano Rodríguez Montiel es Profesor en Letras por la Universidad Nacional del Litoral y becario doctoral del CONICET por el Instituto de Estudios Críticos en Humanidades (IECH-UNR). Actualmente se encuentra finalizando el Doctorado en Literatura y Estudios Críticos de la Universidad Nacional de Rosario. Su tesis, dirisida por Sandra Contreras y Analía Gerbaudo, estudia la constitución del anacronismo como forma del dandismo contemporáneo en la narrativa de Alan Pauls.

Contato: rodriguezmontiel.e@ hotmail.com

Argentina 
PALABRAS CLAVE:

Ficción del origen;

Autofiguración; Infancia;

Lectura; Literatura argentina

contemporánea.

KEYWORDS: Origin

fiction; Childhood;

Imposture; Autofiguration;

Contemporary Argentinian

Literature.
Resumen: este trabajo se propone explorar y analizar los componentes formales, teóricos y autofigurativos a las que Alan Pauls apela para construir, en el pasaje final de La vida descalzo, su ficción del origen como lector. Poniendo en marcha lo aprendido de sus maestros literarios (Borges, Puig, Cortázar y Piglia), Pauls pergeña un relato de iniciación a la lectura con el propósito de que la máquina de sentido que sostiene y legitima tanto a su obra como a su imagen autoral se afirme-asimile y afilie- a un mito fundacional específico: la de una infancia feliz gracias a la ficción. La hipótesis sostiene que esta fábula figura el lugar discipular que Pauls desea para sí en la literatura argentina, uno que, entre la rebeldía y la legitimación, pivotea entre dos grandes identidades: la del «alumno ejemplar», que ostenta un lugar privilegiado junto a los hacedores del canon, y la del «enfant terribles, al que se le consiente y permite todo.

Abstract: The aim of this paper is to explore and to analyze the set of formal, theoretical, and self-figurative elements which Alan Pauls appeals to build, in the final scene of La vida descalzo, his fiction of origin as a reader. Following the teachings of his literary masters (Borges, Puig, Cortázar and Piglia), Pauls creates his story of initiation to reading with the purpose that the meaning wich legitimize both his literary work and his authorial image is affirmed to a specific foundational myth: A happy childhood thanks to fiction. My hypothesis is that this inaugural story reflect to disciplic place wich Pauls wishes for himself in Argentine literature. 
Así como hay un niño Borges (que se ensimisma en los libros ingleses de su padre mientras afuera, en "el Palermo del cuchillo y la guitarra", se cultivan los destinos que escribiría después), un niño Cortázar (al que, autista nato, el médico le prescribe - por su salud - no leer tanto, exigiéndole airearse un poco por su barrio de Banfield), un nińo Puig (que a los cuatro ańos empieza a ir al cine todas las tardes, diligentemente a la seis, a trocar por un rato la insipidez de su General Villegas por el fulgor hollywoodense) y un niño Piglia (que a los tres años, sentado en la vereda de su casa de Adrogué, lee un libro al revés), hay, también, por supuesto, un niño Pauls (Borges, 1930, 41; Cortázar, 1977; Pauls, 1986, 5; Piglia, 2015, 11). Alumno modelo de esta escuela del escapismo, apóstol entusiasta de esta religión bibliófila, el niño Pauls obtiene su diploma de lector - la licencia habilitante para formar parte de esta comunidad consagrada a deificar la ficción y demonizar el mundo entero - en el pasaje final de La vida descalzo. Una escena a todas luces axial cuya estrategia autofigurativa ${ }^{1}$ viene a cumplimentar el único requisito hasta el momento faltante para ser reconocido como tal, a saber, una ficción del origen:

1 Toda vez que en el curso de este trabajo se conjure la noción de autofiguración se estará haciendo subrepticiamente referencia a lo formulado por Silvia Molloy (1996:19). Tal y como afirma Giordano, "desde que Sylvia Molloy lo impuso en el campo de la crítica latinoamericana, el sentido del concepto de autofiguración casi no requiere explicaciones. Como se sabe, mientras rememoran o registran el paso de sus vidas, los escritores figuran, a través de múltiples recursos y estrategias retóricas, imágenes de sí mismos por las que esperan ser reconocidos (estos procesos movilizan representaciones que conciernen tanto a la esfera pública -las llamadas "imágenes de escritor", por ejemplo- como a la esfera privada -figuraciones familiares, amorosas, de género). Las estrategias autofigurativas son al mismo tiempo inter y transubjetivas: los escritores se autorepresentan para otros, desde Otros, es decir, según las posibilidades de cada época, conforme a los imaginarios sociales que definen en cada momento lo que es aceptable o deseable en términos de intersubjetividad" $(2013,3)$. 
En la escena hay un chico. Tiene diez u once años. Está de vacaciones en la playa, un lugar que asocia con la forma más perfecta de la felicidad (...) Un día se despierta, traga, siente alguna molestia en la garganta. Tiene unas líneas de fiebre. Deciden que se quede en casa. El chico reacciona mal y se amarga: es un día espléndido (...) Se mete en la cama: el fresco de las sábanas recién cambiadas le da escalofríos (...) Piensa en todos los juegos que no jugará, todas las olas que no barrenará, todos los helados que no comerá, todas las veces que no meará en el agua (...) y mientras arrima el vaso de jugo y se acomoda en la cama y abre el libro, se da cuenta casi con escándalo que no está triste, que la oscuridad le gusta (...), que no necesita nada ni a nadie (...) y que el libro que acaba de abrir y que ya cierra su trampa sobre él (...) es, como lo demostrarán las cuatro horas ininterrumpidas que pasará con él (...) el otro lugar que tiene la forma de la felicidad perfecta, y que, como escribió alguien a quien él leerá recién veinte años más tarde, cuando ya no esté circunstancial sino crónicamente enfermo, tanto que sólo será capaz de hacer lo único que quiere hacer, quemarse los ojos leyendo, quizá no haya habido días en nuestra infancia más plenamente vividos que aquellos que creímos dejar sin vivirlos, aquellos que pasamos con el libro por el que más tarde, una vez que lo hayamos olvidado, estaremos dispuestos a sacrificarlo todo (2006, 123-125).

«Primero lector, luego escritor»: izada con orgullo, esta frase-bandera bien puede flamear a modo de adagio en la academia a la que el Pauls adulto asiste para aprender no cómo escribir (en 2006 cuenta ya con cuatro novelas, un Premio Herralde y una copiosa producción crítica), tampoco cómo actuar como uno (sin esfuerzo ni desgano, sacando provecho de su genética dandi, Pauls hace del presente - mediático, periodístico y académico - su hábitat natural: concede entrevistas, expone en congresos, goza de residencias en Europa, exhibe su rostro regularmente en la TV) sino, en un orden más básico y pre-profesional, más lúdico y menos funcional, para saber cómo construir una historia que revele cómo se hizo lector. Cuáles fueron 
las condiciones y las razones, dicho de otra manera, que lo llevaron a tener un destino literario. No se trata aquí de indagar en lo que Julio Premat, al teorizar sobre los inicios de la escritura literaria, define como «relato de comienzo» $(2016,147)$. Antes que relatar y resemantizar en el presente los modos en que se inaugura una obra (operación que Pauls ejecuta con todo detalle en el posfacio a la reedición de su primera novela), la escena de iniciación a la lectura referida en la cita responde, más bien, a lo que Piglia denomina, al reflexionar sobre el doble linaje borgeano, relato secreto: "Hay una ficción que acompaña y sostiene a la ficción" de un autor, "un relato fracturado, disperso", en el que éste se imagina las raíces de su literatura (Piglia, 1993, 102). Al igual que la diligencia de Borges por reconocerse como un auténtico ratón de biblioteca que siempre necesitó el mundo a distancia ("Si tuviera que señalar el hecho capital de mi vida, diría la biblioteca de mi padre. En realidad, creo no haber salido nunca de esa biblioteca”), al igual que la voluntad acérrima de Cortázar por mantenerse recluido en su pieza de Banfield ("mi madre, desde los 9 años, me dijo que había que pescarme del cuello y sacarme un poco al sol porque yo leía demasiado”), del mismo modo en que Puig, totalmente enajenado en el corazón de La Pampa seca, se embelesaba con los rostros de Rainer, Dietrich y Garbo ("Yo rechacé totalmente la realidad que me tocó vivir (...) tomé al cine, en cambio, como 'la realidad', mi realidad"), y así como Piglia, autoconsciente desde la cuna de haber sido programado para esto, buscó adquirir sin saber leer su DNI de lector ("yo estaba ahí, en el umbral, haciéndome ver, cuando de pronto una larga sombra se inclinó y me dijo que tenía el libro al revés”), lo que 
Pauls desea, en resumidas cuentas, es que la máquina de sentido que sostiene y legitima tanto a su obra como a su imagen autoral se afirme - asimile y afilie - a un mito fundacional: la de una infancia feliz gracias a la ficción, al tiempo sin tiempo y al mundo sin mundo que provee la experiencia de la lectura; una escena épica que cifra, de entrada y para siempre, un vínculo indeleble entre literatura y vida (Borges, 1999, 24; Puig, 1977; Cortázar, 1977; Piglia, 2015, 11).

La elección de este plantel docente no es arbitraria: funcionando como un genuino diario de clase en el que, de forma intermitente pero manifiesta, el discípulo registra lo mucho que ha aprendido de sus maestros, se detectan en la producción crítica de Pauls ciertos pasajes confesionales que sitúan a este colectivo en el rol de fundamento, credo, horizonte hacia el cual proyectar. Porque, menos interesados en el arte de enseñar a cómo leer a otros, antes que una alfabetización de carne y hueso centrada en los rudimentos básicos de la praxis crítica, el magisterio impartido por Borges, Cortázar, Puig y Piglia contribuye a la formación de otro tipo de experticia, uno que sólo los escritores - ¿muertos y admirados?- pueden atreverse a infundirlo: la posibilidad de inventar, con la misma caja de herramientas con la que se fabrica la ficción, un ideal, una utopía, una «vida de lector»².

2 Sobre sus dos maestros de carne y hueso, responsables de un influjo decisivo en su quehacer crítico, Pauls escribe: "Jorge Panesi (primer dealer de lecturas, artista del dar a leer, culpable del único trofeo bibliófilo del que le gusta vanagloriarse: la primera edición del Ferdydurke [Argos, 1947], regalada un anochecer legendario de 1974 en un bar de Corrientes y Uruguay). China Ludmer (gurú de la astucia, el saqueo y el sesgo, trípode esencial de una pedagogía lectora que solo cree en el resto, la disonancia y las intuiciones contraintuitivas. Él, que le deberá todo lo que no le debe ya a Panesi, no llega a terminar su primer libro, Cien años de soledad. Una interpretación 
Así, distribuyéndose las funciones y unidades - haciendo valer la madera de la que están hechos -, la cátedra Borges enseña qué puede un lector (" $\mathrm{La}$ gran pregunta borgeana no es, como se esperaría, ¿cuál es el poder de la literatura? Sino ¿qué puede un lector? Y la respuesta es: todo. El lector según Borges lo puede todo"); la cátedra Cortázar ilustra cómo domiciliarse para siempre en la literatura ("Rayuela me integraba: había ahí un lugar, no sólo para mí (...) sino para mi yo ideal, para todo lo que yo deseaba de mí, todo lo que imaginaba para mí, todo lo que me veía escribiendo cuando fuera el escritor que algún día, hoy, si me descuido, terminaría siendo”); la cátedra Puig, tótem al que el alumno Pauls nunca dejará de invocar y reversionar, advierte sobre los efectos de la lectura, sobre de lo que ocurre, a decir verdad, si uno cae en la trampa - hechizo, quimera, droga - que el libro tiende sobre uno ("Empieza a ver el mundo a través del libro [...], el efecto es una suerte de emanación oblicua, de atmósfera o de música, que se posa sobre todas las cosas y les deja una especie de polvillo leve - solo en Manuel Puig reconoce un efecto parecido - que no se puede quitar") (Pauls, 2012, 192; $2014,15 ; 2018,34-35)^{3}$.

[...] cuando el librero, el escritor Luis Guzmán, le comenta que la autora da clases particulares y le da su teléfono. Pasa tres ańos estudiando con ella en grupo; tres años a razón de una vez por semana, los miércoles, de siete a once de la noche, alrededor de una mesa grande y redonda [...] Todo lo que haga después, cada palabra que escriba o lea, habrá nacido de ahí) (Pauls, 2018, 65-66).

3 Como un yonqui, Pauls vuelve siempre a caer en Puig. Leonardo Berneri, con tino, grafica muy bien esta reincidencia: "Puig ofrece a Pauls todo lo que busca, da las notas que sus lecturas requieren. Aparece, reaparece, no deja de aparecer en la ensayística paulsiana incluso más que Borges. Puig es una obstinación, una insistencia en una escritura siempre a la espera de invocarlo, de crearle herederos, de atribuirles cortes e inauguraciones: "Puig como desestabilizador de las 
Ahora bien, es al llegar a la cátedra Piglia cuando la cuestión del origen - de cómo aprender a inventarlo - desnuda, al mismo tiempo, toda su complejidad $\mathrm{y}$ toda su potencia. En Trance, el glosario de lectura que emula formalmente el Barthes por Barthes, Pauls hace pasar por suyo el mito originario del nińo Piglia, ese mismo que el propio Piglia comunica al mundo apenas tres años antes, en las líneas inaugurales del primer tomo de sus diarios. La operación, a todas luces consciente, a todas luces inverosímil, pone a la vista qué tipo de saber es el que se cincela y se transmite en aquella sala para aspirantes, qué es lo que Pauls discípulo, en otras palabras, aprehende, mimetiza y vampiriza de la sabiduría de su mentor: el arte de la impostura. ¿No es Piglia quien, persiguiendo una utopía personal - que su vida sea leída y legitimada con los valores que sustentan su ficción -, comete la mayor impostura, la más irremisible de todas, al transferirle la responsabilidad autoral a Emilio Renzi, su álter ego estetizado? ("Yo - confiesa al promediar la mitad de 327 cuadernos, el documental de Andrés Di Tella - a veces tengo la fantasía de publicar el diario como el diario de Emilio Renzi. Es decir: darle a un personaje que he construido a lo largo de los libros mi vida") (Di Tella, 2015, s/p). Si en Piglia este recurso de corrección e invención del pasado, este ejercicio de fabulación bajo las órdenes del anacronismo, tiene el acento puesto en el futuro (en la autoconstrucción utópica de una posteridad), el relato secreto de Pauls responde, más bien, a un anhelo inscripto en el presente: terminar

identidades monolíticas, Puig como deconstructor de los discursos de la autoridad, Puig banal, disidente, marginal, político solo desde esa marginalidad, Puig antinacionalista, posmoderno avant la lettre" (Berneri, 2019, 107). 
de escriturar su plaza en la tradición nacional, ese lugar que él piensa para sí y sobre el que su narrativa viene edificando desde su apertura. Una zona que, similar a una residencia comunitaria, a la vez pensión y guarida, se encuentra poblada por una "vasta y secreta familia de singulares":

Mito inaugural. En su escena originaria de lector, tiene tres o cuatro años y ha salido de paseo por el barrio con su abuela. De golpe (...) se ve sentado en el cordón de la vereda con un libro en las manos, "leyendo". Es un libro de "adulto", es decir, un texto puro, en el que fija los ojos con una concentración extrema, como hipnotizado. Hasta que su abuela, volviendo de algún mandado, se acuclilla junto a él y se lo da vuelta entre las manos, poniéndolo en posición correcta (...) Cuenta la escena a menudo hasta que un día la lee contada por otro casi en los mismos términos. Es difícil describir lo que siente. Cierto estupor, naturalmente, porque no es común encontrar escrito en el mundo, reivindicado por otro (...), lo que consideraba el colmo de lo íntimo y lo propio (...) Pero los minutos corren y el hecho de que sea la escena originaria de otro lector, que antes parecía delatar su inautenticidad, sino su comportamiento delictivo, ahora, al revés, le suena como una garantía o una confirmación (...) Por una extrańa torsión, todo lo que lo acusaba de plagiario ahora lo ratifica y apuntala en su verdad, y la escena originaria de lectura le pertenece más que nunca (...) Inconfundible y compartida, única y común, se trata sin duda de una singularidad peculiar, que lo distingue tanto como lo afilia. ¿Y si ese lector infans, que lee antes de poder leer y persiste, imperturbable, una vez desenmascarada su impostura, y si esa imagen de lector íntima, entrañable (...) no fuera más que un arquetipo de primer lector, un ready-made que los aspirantes a escritores pudieran buscar y elegir (en los Diarios de Emilio Renzi de Piglia, aquí mismo, en cualquier otra parte), y volver suyo al instante, como él hizo con Piglia, o Piglia con él, o ambos con algún otro, miembros todos de una secreta y vasta familia de singulares? (Pauls, 2018, 70-71).

4 Y, por si fuera poco, un tercero en discordia viene a sentarse a esta mesa de negociación entre impostores, reclamando parte de las regalías que por derecho le corresponden. En Diferencia y repetición de 1968, Deleuze traspapela en la página 159 lo que bien puede ser considerado como el eslabón perdido de esta serie, la génesis jamás citada, el pasaje-fuente callado durante todos 
Corregida la miopía para ingresar, con mejor vista, a la escena que inaugura esta lectura, montado el escenario con las piezas necesarias para revisitar, ahora sí, las capas de sentido que traman esta ficción del origen, distingamos, por separado, la impronta - el eco fantasmático - de esta academia-familia recién apuntada:

a) ¿Qué puede, cuando lee, el niño Pauls? Sacrificarlo todo: esta audacia, condensada hiperbólicamente en el «Todo», concentra al mismo tiempo una definición de carácter funcional (antes que por lo que es, el lector se define borgeanamente por lo que puede: todo), y un valor a partir del cual tasar favorablemente aquello que se lee (el «todo» es una fórmula que Pauls acostumbra a utilizar como remate auspicioso en sus intervenciones críticas: Barthes "lo sacrifica" todo, a Piglia "le debemos" todo, Fogwill "lo tenía" todo, Fellini "lo dio absolutamente todo", y así) (Pauls, 2012, 73; 109; 110; 264).

b) ¿Qué busca, cuando lee, el niño Pauls? El otro lugar: cortar con el mundo para volverlo habitable, hacer del tiempo y del espacio un verdadero agujero negro autosuficiente, es el proyecto máximo de este infante al leer. Porque, convertido el orden telúrico en una zona franca incomunicable -esa que, a la vez intempestiva y atópica, configura las coordenadas espacio-temporales de sus ficciones-, el acto de leer deviene trance, es decir, experiencia de transporte, de pasaje o de contagio entre el lector

estos años: "No es correcto hablar de egocentrismo en el niño. El niño que empieza a manipular un libro por imitación, sin saber leer, no se equivoca jamás: lo pone siempre al revés. Es como si lo tendiese a la otra persona, término real de su actividad, al propio tiempo que capta él mismo el revés como foco virtual de su pasión, de su contemplación profundizada” (Deleuze, 1968, 159). 
y el libro, entre la vida y la ficción: "se lee porque hay hiato (...) y se lee para hacer algo con él": instalarse, integrarlo, colmarlo $(2018,46)$. Una peripecia de traslación que se origina, en tanto hito posible de fechar en la cronología del escritor, por Los premios, la protagonista tácita, para nuestro contento documentalista, del pasaje que principia este argumento: "recuerdo que la leí durante un verano pródigo en anginas en Miramar, la ciudad balnearia más fea del universo" $(2014,7)$.

c) ¿Qué efecto produce, cuando lee, el niño Pauls? La forma de la felicidad perfecta: consecuencia directa del ítem anterior, al punto de traspapelarse sin remedio al querer discernirlas entre causa y efecto, motivo y resultado, procedimiento y producto, la experiencia de trance - "la asincronía fundamental" (29) que provee el ostracismo de la lectura- no proporciona otra vivencia que una por completa feliz: “en pleno trance lector, cuando hace de cuenta que el mundo ha desaparecido con todo adentro, incluido todo lo que él ama menos lo que lee (...), se ve a sí mismo con su libro y se dice muy suavemente (...): "Soy feliz" (32). La relación de la lectura con la vida no es, en este sentido, "de oposición, ni de exclusión, ni de enseñanza, ni de complementariedad, sino pura y simplemente" de felicidad: la lectura es un juego de deserción y de desplazamiento, pero también de fabulación y aditamento, de agregar, como lo hizo ininterrumpidamente el niño Puig, mundos al mundo: "Se lee para vivir tanto como para evitar vivir; se lee para saber qué es vivir y cómo vivir; se lee para escapar de la vida e imaginar una vida posible” $(2018,89)$ ”. 
d) ¿Qué clase de lector es, cuando lee, el niño Pauls? Un impostor: al igual que su maestro Piglia, un artista del montaje y del "citar sin comillas" (un tic o virus trasmitido, también a él, por otro mentor de Pauls: Borges), en las líneas finales de la afamada escena de La vida descalzo aparece diluida, por no decir encubierta, una cita de "Sur la lecture" de Proust $(2012,108)^{5}$. Este solapamiento de identidades, esta sutura de yoes sobre una misma voz que se aventura al ejercicio confesional, deja a las claras la especie lectora a la que Alan Pauls pertenece y aquella que milita con fervor: una que, con libertad absoluta, sacándole rédito a su condición de poderlo todo, concibe a la «vida» no como una entidad sacra a la que se le debe rendir culto únicamente con el folklore de la verdad (el afán de ella) sino, más bien, como un material más para ser leido, esto es, disponible para ser labrado, trocado, pervertido en el laboratorio de la escritura. La vida, para un dandy como lo es Pauls, no puede dejarse al arbitrio de los valores que cimentan, en su sentido más vulgar, la práctica de la confidencia (léase búsqueda de autenticidad, franqueza, espontaneidad); lejos de presentársele como un stock de testimonios fidedignos, debidamente procesados e inconmovibles del que sólo se espera un único uso (su reproducción), la vida se monta en Pauls como un teatro o película: pura actuación, montaje, performance, acomodada para ser travestida -interferida- con diferentes máscaras, en este caso una muy conocida: la de Proust.

$5 \quad$ Transcribimos el párrafo: "Il n'y a peut-être pas de jours de notre enfance que nous ayons si pleinement vécus que ceux que nous avons cru laisser sans les vivre, ceux que nous avons passés avec un livre préféré" (Proust, 2012). 
Es así cómo, valiéndose de una capacidad (la omnipotencia), una actividad (el escapismo), una búsqueda (la felicidad) y una identidad (la impostura), el Pauls adulto pergeńa su semblanza primigenia como lector. Un relato secreto o ficción del origen cuya ilustración, si por una extraña razón se le exigiera, a último momento, que la breve biografía que acaba de finiquitar como trabajo final venga acompañada de una fotografía, bien podría ser la siguiente:

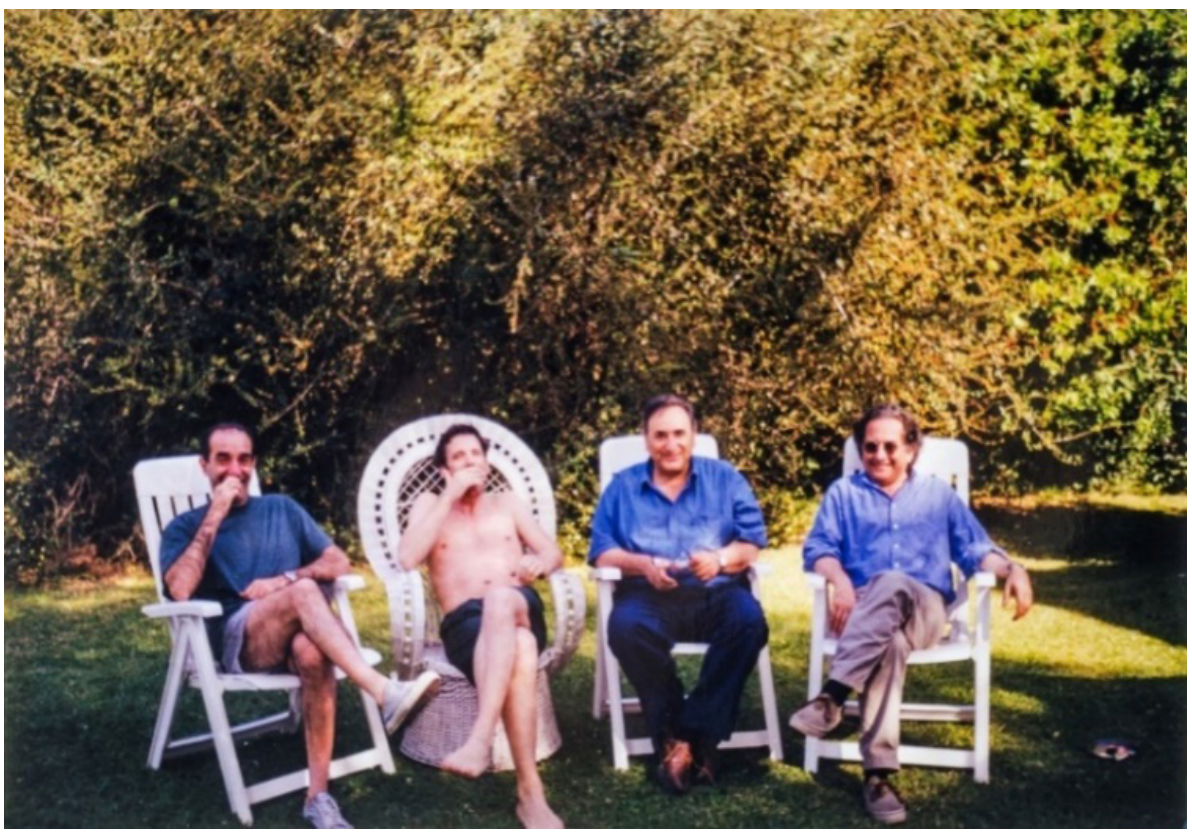

Figura 1: Fotografía exhibida en la muestra "Conexión Saer"".

Fuente: Muestra "Conexión Saer"

6 De forma itinerante, y bajo la curadoría de Martín Prieto y María Teresa Constantin, la imagen se expuso entre 2017 y 2019 en varias galerías, salas y museos del país, como el Museo "Rosa 
Antes que su marco (el cual, a la vez estival y caluroso, diurno y bucólico, reproduce una escena típica de sobremesa argentina), antes que su historia (cuyos pormenores felizmente nos llegan a través de Piglia) ${ }^{7}$, incluso más allá de los intérpretes que lo escoltan - entre la cofradía y el club, la amistad y la complicidad, a todos se les puede asignar una embajada en la Nación Pauls: Marcelo Cohen (La Traducción), Juan José Saer (La Narración); Ricardo Piglia (La Crítica)-, lo que nos interesa aquí, lo que hace que esta imagen funcione como portada del mito inaugural paulsiano, no es otra cosa que aquello que al leer la gimnasia de la afectación dandy llamamos actitud. Porque, la desfachatez de mostrarse en cueros, descalzo y en short mientras todos los demás, mayores que él, se presentan arropados y calzados (el colmo del porte señorial es, por supuesto, Saer): ¿no figura acaso el lugar eternamente discipular que Pauls desea para sí en la literatura argentina y que su fábula de iniciación lectora vendría furtivamente a enunciar? Discipular, es decir: un mocoso entre adultos que se da el lujo, entre la rebeldía y la legitimación, la libertad y la protección, de pivotear entre dos grandes identidades: una como «alumno ejemplar», consentido y favorito, que ostenta un lugar privilegiado al posar junto con los hacedores del canon, y otra como «enfant terrible»,

Galisteo" de Santa Fe, la Plataforma Lavarden en Rosario y la Fundación OSDE de Buenos Aires, entre otros (Conexión Saer, 2018).

7 "Horacio había llegado imprevistamente a la quinta que alquilaban aquel verano en las afueras, con Gerardo y Ana y otros amigos que iban y venían, incluido Juani, que había llegado de Francia a fines de marzo y se había quedado un par de días con ellos, y había una foto donde Emilio estaba con él y con Alan y con Marcelo Cohen, medio desnudos en pantalón de baño salvo Saer, que sonreía con cierto aire de resignación pero de saco y corbata, como un bancario — «de punto y banca», había aclarado, ensillado y jovial_-" $(2017,146)$. 
malcriado y desobediente, al que se le conciente todo, incluido exhibirse casi desnudo en la única silla-trono del lugar.

¿Qué hace un niño travieso frente a la biblioteca? ¿Qué deporte practica un pícaro ilustrado que "descubre muy temprano que nada le importa más que leer", que "lee todo lo que puede y lo que encuentra" y "hasta lo que no entiende"? ¿Cómo colma su apetito de bribón alguien que "por fuera de leer" considera toda actividad terrenal "una frivolidad o un escándalo"? (Pauls, 2018, 7;16). Glotón y juguetón, supervisado por la mirada benefactora de sus adultos responsables, la criatura Pauls se entrega por completo al goce de la profanación: un arte impune que consiste en expropiar - desvalijar, saquear, arrasar - todo lo que allí interesa y usarlo a voluntad. De allí que cuando sea el turno de fraguar su ficción del origen como escritor opte por contar, modificar y ampliar - no una o dos jsino tres veces! - un mismo delito escolar: la vez que el profesor Le Prix lo aplaza - a él, "su mejor estudiante", "el más aventajado" - por entregar apócrifamente bajo su autoría un poema de Jacques Prévert (Montes-Bradley, 2005; Pauls, 2002, 43; 2012, 330). Transcribimos a continuación la versión más completa de la anécdota:

Pasaron ya más de cuarenta años desde la mañana aciaga (...) en que un profesor de francés llamado Le Prix (...) le reveló a su mejor estudiante cuál era su destino. Devolvía corregidos los últimos trabajos hechos en casa: una poesía "personal" (...), de tema y extensión libres, que todo el mundo, conciente de su paladar exigente, había entregado en estado de máxima incertidumbre. Los devolvía según su técnica especial de suspenso, de peor a mejor, primero las notas más bajas, después, en rigoroso orden creciente, las más altas, regodéandose en comentar las primeras y escupiendo las segundas con una expeditiva satisfacción. Ya casi no quedaban hojas en sus manos (...) y la del estudiante más aventajado aún no había sido anunciada. Vinieron en rápida seguidilla dos ochos, un 
nueve, el previsible nueve cincuenta de Venanzi y sus jumpers ultracortos, hasta que quedó una hoja, una sola, que el profesor sopesó y examinóun rato largo, mesándose la barba con unos remolinos pensativos. "Y el diez es para Jacques Prévert", dijo por fin, alcanzándome la hoja sin mirarme, "un poeta popular que el seńor Pauls parece haber memorizado muy bien. Pase al frente, Pauls, y tenga a bien compartir con el resto de sus compańeros ese concepto tan original que tiene de lo que es una 'poesía personal'. Me acusaron de plagiario y me hice escritor. Me desenmascaron en público y me condenaron a ser un impostor" (2012, 330).

Lectura » impostura » destino literario: tal es la cadena productiva, la serie de pasos o instancias sucesivas, a la que la Fábrica Pauls somete todas sus máquinas y operarios para labrar, de forma gemela, su acta de nacimiento como lector y escritor. El hilo narrativo que alega, en otras palabras, las razones por las cuales el niño Pauls termina matriculando su vida a la literatura es, en uno y otro caso, el mismo: se lee (formas, saberes, problemas, mundos), se extrae una cédula de identidad de aquello que se lee (gestos, voces, entonaciones), y se la hace pasar por suya. “¡Cómo me interesa la cuestión de la impostura! - exclama un joven Pauls sentado junto a un joven Aira y a un joven Chefjec en un congreso en Rosario. A veces llego a pensar que no hay ninguna otra cuestión. Ninguna”. Y aclara, por si faltara más: "yo fui un impostor de chico, de muy chico - a eso se reduce toda mi procacidad, digo: mi precocidad, de la que tanto se ha hablado en la prensa -, y probablemente vuelva a serlo en unos años, de viejo, cuando ya no me quede energía para ser original” (2002, 43).

La autoconstrucción de un autor es, siguiendo a Sylvia Molloy, siempre un acto retrospectivo: su alumbramiento nunca ocurre en tiempo y forma, 
sino que, luego de aprender a caminar y valerse por sí mismo - luego de levantar una obra lo suficientemente avezada para tornar su genealogía un problema de interés literario -, el escritor vuelve sobre sus pasos y revisita los escombros de su pasado. Salvo que, más que una sala de parto, antes que los archiveros atiborrados del registro civil, lo que recorre este excursionista del tiempo es la escena de un crimen: muerta la persona, perdido para siempre el pretérito preliterario, el autor (re)lee su propia vida en busca de un rostro. Y es ahí, en ese acto de antemano estéril (la exhumación impoluta de su materia fósil) cuando el escritor confecciona su propio identikit. Uno a gusto, claro está, porque lo que importa no es encontrar el verdadero cadáver - eso que, orgullosos, los anticuarios llamarían «la verdad del sujeto»-, sino algo más rentable, más acorde al presente que lo interpela: una credencial idónea, exenta de ignominias, para proyectarse en lo público.

\section{REFERENCIAS BIBLIOGRÁFICAS}

Berneri, Leonardo. "Retrato del escritor disidente: acerca de la ensayística de Alan Pauls”. In: Perifrasis (10), 19, 2019, 97-110.

Borges, Jorge Luis. Evaristo Carriego. Buenos Aires: Sudamericana, 1930.

Borges, Jorge Luis. Autobiografía (1899-1970). Buenos Aires: El Ateneo, 1999.

Cortázar, Julio. "Julio Cortázar a fondo". Entrevista concedida a J. Soler Serrano. In: A fondo [Transmisión televisiva]. Barcelona: Radiotelevisión Española, 20 mar. 1977. Disponível em: https://www.youtube.com/watch?v=ppon2ldpJwU. Acesso em: 07 mai. 2021.

Deleuze, Gilles. Diferencia y repetición. Buenos Aires: Amorrontu, 1968. 
Di Tella, Andrés (director). director. 327 cuadernos. Gema Films y Lupe Films, 2015.

Giordano, Alberto. "Autoficción: entre literatura y vida". BOLETIN/17 del Centro de Estudios de Teoría y Critica Literaria, 17, 2013, 1-20. Disponível em: https:// www.cetycli.org/cboletines/cd98f00b20-albertogiordano17.pdf. Acesso em: 07 mai. 2021.

Molloy, Sylvia. "Introducción". In: Actos de presencia. La escritura autobiográfica en Hispanoamérica. México: Fondo de Cultura Económica, 1996, 11-22.

Montes-Bradley, Eduardo (prod.) y Guebel, D. (Dir.). Si yo fuera realmente libre: Alan Pauls. Buenos Aires: Contrakultura films/Heritage Film Project. 2005. Disponível em: <https://vimeo.com/99396320>. Acesso em: 07 mai. 2021.

Pauls, Alan. Manuel Puig: La traición de Rita Hayworth. Buenos Aires: Hachette, 1986.

Pauls, Alan. El factor Borges. Barcelona: Anagrama, 2000.

Pauls, Alan. “Interminable. Un diario íntimo”. In: Nueve perros (2), 3, 2002, 42-50.

Pauls, Alan. La vida descalzo. Buenos Aires: Sudamericana, 2006.

Pauls, Alan. Temas lentos. Selección y edición de Leila Guerriero. Santiago de Chile: Universidad Diego Portales, 2012.

Pauls, Alan. “¿Qué hacer con la gente vulgar?”. In: Cuadernos Hispanoamericanos, 772, 2014, 4-22.

Pauls, Alan. Trance. Buenos Aires: Ampersand, 2018.

Piglia, Ricardo. "Borges y los dos linajes". In: La Argentina en pedazos. Buenos Aires: Ediciones de La Urraca, 102-105, 1993.

Piglia, Ricardo. Los diarios de Emilio Renzi. Años de formación. Barcelona: Anagrama, 2015.

Piglia, Ricardo. Los diarios de Emilio Renzi. Un día en la vida. Barcelona: Anagrama, 2017. 
Premat, Julio. Érase esta vez. Relatos de comienzo. Buenos Aires: Eduntref, 2016.

Proust, Marcel. “Sur la lecture”. Paris: Éditions de La République des Lettres, 2012.

Puig, Manuel. "Manuel Puig a fondo". Entrevista concedida a J. Soler Serrano. A fondo [Transmisión televisiva]. Barcelona: Radiotelevisión Española, 30 out. 1977. Disponível em: <https://www.youtube.com/watch?v=rXxlo1kPvpg>. Acesso em: 07 mai. 2021.

\section{FIGURAS}

Figura 1. Fotografía exhibida en la muestra "Conexión Saer". In: Año Saer, Ministerio de Innovación y Cultura de Santa Fe, 2016-2018. Recuperado de: <http://conexionsaer.gob.ar/catalogo-conexion-saer/>. Acesso em: 17 mai. 2021. 
